\title{
Comparison of Lipid Profiles among the Women with or without Oral Contraceptive Pill Users
}

\author{
Abida SULTANA ${ }^{1}$, Shamima RAHMAN ${ }^{2}$, Al Mamun Mahbub ALAM ${ }^{3}$
}

\begin{abstract}
${ }^{1}$ Senior Consultant, Department of Gynaecology \& Obstetrics, Dhaka Medical College \& Hospital, Dhaka, Bangladesh; ${ }^{2}$ Junior Consultant, Department of Gynaecology \& Obstetrics, Dhaka Medical College \& Hospital, Dhaka, Bangladesh; ${ }^{3}$ Senior Scientific Officer, Institute of Epidemiology, Disease Control \& Research, Dhaka, Bangladesh
\end{abstract}

[Reviewed: 30 January 2016; Accepted on: 1 March 2016; Published on: 1 July 2016]

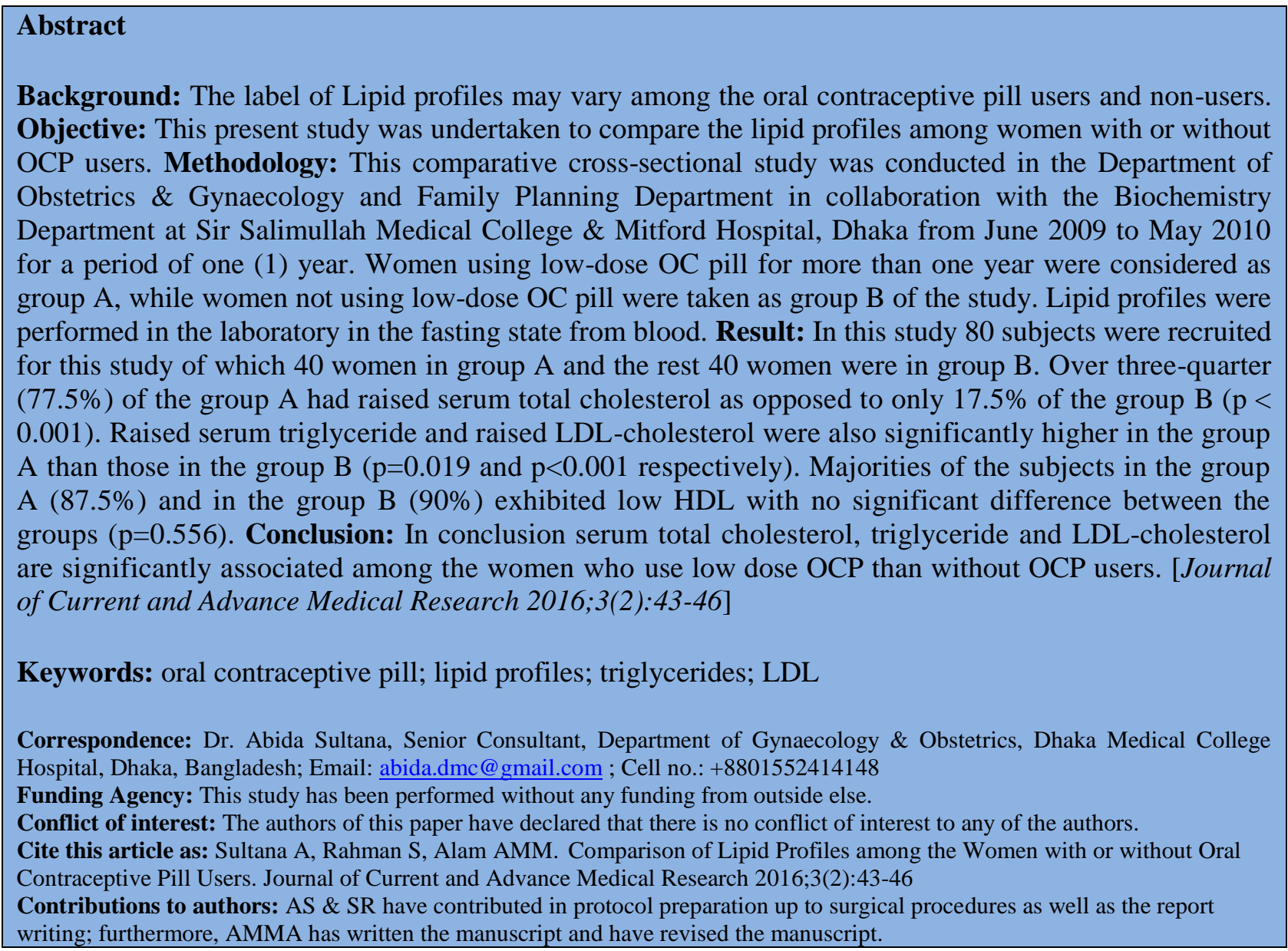

\section{Introduction}

The hormonal components of oral contraceptives exert major effects on plasma lipoprotein metabolism ${ }^{1}$. Estrogens may increase production of plasma triglycerides, leading to increase levels of very low density lipoproteins ${ }^{2}$; however these may also reduce levels of cholesterol enriched and potentially atherogenic intermediate- and lowdensity lipoproteins ${ }^{3}$. Progestogens increase LDL absorption and decrease HDL absorption by 
increasing absorption of apo-B and decrease absorption of apo- $\mathrm{A}^{4}$.

A large number of Bangladeshi women of various socio-economic statuses using low dose $\mathrm{OCP}^{5}$. Shukhi is mostly used by the women of low socioeconomic status, because the family planning program of the Government of Bangladesh made it available to them free of cost and contains $30 \mu \mathrm{gm}$ ehinyloestradiol (EE) and $150 \mu \mathrm{gm}$ lovonorgestrol $(\mathrm{LNG})^{6}$.

There is a definite dose-dependent relationship with both estrogen and progestogen, although the mechanisms of risk may be different; estrogen influencing the coagulation system, whereas the progestogen influencing the lipid metabolism and blood pressure ${ }^{7}$. Therefore this present study was planned to compare the lipid profiles among the women with or without OCP users.

\section{Methodology}

This comparative cross-sectional study was carried out in the Department of Obstetrics \& Gynaecology and Family Planning Department in collaboration with the Department of Biochemistry at Sir Salimullah Medical College (SSMC) \& Mitford Hospital, Dhaka from June 2009 to May 2010 for a period of one (1) year. Women with the age group of 20 to 40 years who were using low-dose oral contraceptive pill (OCP) containing $30 \mu \mathrm{gm} \mathrm{EE}$ plus $150 \mu \mathrm{gm}$ LNG for more than one year were selected as group A and women who were not using low-dose OCP were selected as group B. Women presented with systemic diseases like liver and renal diseases, women with hypertension and diabetes, history of using beta-blockers, thiazide diuretics, glucocorticoids, smokers and alcoholics, women using other hormonal contraceptives were excluded from this study. Before commencing the research work, permission was taken from the Ethical Committee of SSMC, Dhaka. The required numbers of subjects were purposively included in the study. The demographic variables included in the study were age, socioeconomic status, educational level, weight, height and parity. Serum lipid profiles were measured from all the patients and these were total cholesterol, high-density lipoprotein (HDL)cholesterol, low-density lipoprotein (LDL)cholesterol and triglycerides. Raised cholesterol of total cholesterol in serum was considered if it exceeded >200 mg/dL. Raised triglyceride was considered if triglyceride exceeded $>150 \mathrm{mg} / \mathrm{dL}$. Raised serum LDL was defined raised if it exceeded $>150 \mathrm{mg} / \mathrm{dL}$. Reduced serum HDL was considered if it reduced $<40 \mathrm{mg} / \mathrm{dL}$. In this study low-dose oral contraceptive means pill containing $30 \mu \mathrm{gm}$ of ethinyl estradiol+150 $\mu \mathrm{gm}$ of levonorgestrel (LNG). After selection of study subjects, detailed history was taken and a careful physical examination was done. Subjects were requested to fast overnight (10 to 12 hours) and to report between 8 to 9 am next morning in the Department of Biochemistry at Sir Salimullah Medical Collage \& Mitford Hospital, Dhaka for laboratory tests. Five milliliter of blood was collected from each subject with disposable syringe. From the preserved serum total cholesterol, HDL-cholesterol, LDL-cholesterol and triglycerides were estimated. Collected data were processed and analyzed with help of SPSS (Statistical Package for Social Sciences), version 18.0. The test statistics used to analyze the data were Unpaired " $\mathrm{t}$ " Test and Chi-square Test. The level of significance was set at 0.05 and $p$-value $<0.05$ was considered significant.

\section{Results}

The present study intended to determine the influence of OCP use on lipid metabolism included 40 women who used low-dose OC pills for more than one year designated as group $\mathrm{A}$ and 40 women who did not use them designated as group B. The findings of the study obtained from data analyses are documented below.

Table 1: Comparison of age of the study subjects $(\mathbf{n}=\mathbf{8 0})$

\begin{tabular}{lccc}
\hline Parameters & $\begin{array}{l}\text { Group A } \\
(\mathrm{n}=40)\end{array}$ & $\begin{array}{l}\text { Group B } \\
(\mathrm{n}=40)\end{array}$ & $\begin{array}{c}\mathrm{p}- \\
\text { value }\end{array}$ \\
\hline Age (year) & & & \\
Mean \pm SD & $\begin{array}{c}29.40 \pm 4.43 \\
20-40\end{array}$ & $\begin{array}{c}29.23 \pm 4.74 \\
21-40\end{array}$ & 0.865 \\
Range & $20-40$ & \\
$\begin{array}{l}\text { *Data were analyzed using } \\
\text { presented as mean } \pm \text { SD. }\end{array}$ & & &
\end{tabular}

Table 1 shows no significant difference between group A (29.40 \pm 4.43$)$ and group B (29.23 \pm 4.74$)$ regarding age $(\mathrm{p}=0.865)$.

Over three-quarter (77.5\%) of the group A had raised serum total cholesterol as opposed to only $17.5 \%$ of the group B $(\mathrm{p}<0.001)$. Raised serum triglyceride and raised LDL-cholesterol were also significantly higher in the group A than those in the group $\mathrm{B}(\mathrm{p}=0.019$ and $\mathrm{p}<0.001$ respectively).

Majorities of the subjects in either group $(87.5 \%$ in the group A and $90 \%$ in the group B) exhibited 
low HDL with no significant difference between the groups $(\mathrm{p}=0.556)$ (Table 2$)$.

Table 2: Abnormal level of lipids between Study Groups $(\mathbf{n}=\mathbf{8 0})$

\begin{tabular}{|c|c|c|c|}
\hline Parameters & $\begin{array}{l}\text { Group A } \\
(n=40)\end{array}$ & $\begin{array}{l}\text { Group B } \\
(n=40)\end{array}$ & P value \\
\hline \multicolumn{4}{|c|}{ Cholesterol (mg/dl) } \\
\hline $\operatorname{Normal}(\leq 200)$ & $9(22.5 \%)$ & $33(82.5 \%)$ & \multirow{2}{*}{0.001} \\
\hline Raised (> 200) & $31(77.5 \%)$ & $7(17.5 \%)$ & \\
\hline \multicolumn{4}{|c|}{ Triglycerides (mg/dl) } \\
\hline Normal $(\leq 150)$ & $17(42.5 \%)$ & $29(72.5 \%)$ & \multirow{2}{*}{0.007} \\
\hline Raised $(>150)$ & $23(57.5 \%)$ & $11(27.5 \%)$ & \\
\hline \multicolumn{4}{|l|}{ HDL (mg/dl) } \\
\hline Low $(<40)$ & $35(87.5 \%)$ & $36(90.0 \%)$ & \multirow{2}{*}{0.556} \\
\hline Normal $(\geq 40)$ & $5(12.5 \%)$ & $4(10.0 \%)$ & \\
\hline \multicolumn{4}{|l|}{ LDL (mg/dl) } \\
\hline $\operatorname{Normal}(\leq 150)$ & $4(10.0 \%)$ & $32(80.0 \%)$ & \multirow{2}{*}{0.001} \\
\hline Raised (> 150) & $36(90.0 \%)$ & $8(20.0 \%)$ & \\
\hline
\end{tabular}

\section{Discussion}

This cross sectional study has been undertaken to estimate the major serum lipid levels in Bangladeshi women of reproductive age who use oral contraceptive pill for more than one year and to compare their lipid status with those women who do not use oral pills. Serum cholesterol, LDL, triglyceride were significantly raised $(\mathrm{p}<0.001)$ in contraceptive users compared to their non-user counterparts, though the mean HDL level in majority of the subjects of both groups was low with no significant intergroup difference $(\mathrm{p}=$ 0.556). One study ${ }^{8}$ observed that the significantly increased serum triglyceride, total cholesterol, apolipoprotien-B and LDL and slightly decreased HDL level after giving 12 cycles of OC containing EE 20 $\mu \mathrm{gm}$ in combination with levonorgestrel $100 \mu \mathrm{gm}$ which also resemble the present study.

Serum total cholesterols were significantly raised $(>200 \mathrm{mg} / \mathrm{dl})$ in more than three-quarter $(77.5 \%)$ of women who were using oral contraceptives for $>1$ year compared to $17.5 \%$ of women who were not using the same drugs $(\mathrm{p}<0.001)$. Serum triglyceride levels were also found significantly raised in the former group (57.5\%) than that in the latter group (27.5\%) ( $\mathrm{p}<0.05)$. A staggeringly higher proportion of contraceptive users $(90 \%)$ had elevated serum LDL levels as opposed to only $20 \%$ of women among non-users of oral contraceptives $(p<0.001)$. However, serum HDL level was interestingly low among both users and non-users $(p=0.556)$. These findings have similarity with those of Kashefa ${ }^{9}$ who reported increased level of serum cholesterol, triglyceride and LDL and dicreased HDL among contraceptive users. However, a study conducted by $\mathrm{Nahar}^{10}$ (1986) on Bangladeshi women using Ovacon and Maya for 2 years, it was found that serum cholesterol level remained within normal limit. The difference in findings between Nahar's study and the present study might be that sampled population in Nahar's study used contraceptive for 2 years duration and in the present study $50 \%$ of the OCP users had more than 5 years duration of use. One study ${ }^{11}$ observed that the significantly increased serum triglyceride, total cholesterol, apo-lipoprotien-B and LDL and slightly decreased HDL level after giving 12 cycles of OC containing EE $20 \mu \mathrm{gm}$ in combination with levonorgestrel $100 \mu \mathrm{gm}$ which also resemble the present study.

A study was done by Coata et al ${ }^{12}$ of plasma levels of serum lipids were determined in a group of 10 women taking OCs and were compared with those of controls $(n=10)$. The blood parameters were evaluated before OC pill use and thereafter at 3 and 6 months. The metabolic impact on OC on serum lipids showed that cholesterol and triglycerides tend to increase after 3 and 6 months of OC pill use bearing consistency with findings of the present study. They also found a significant increase of high density lipoprotein and apolipoprotien A-1 which is not consistent with the findings of the study. In the present study majority of the women in either group had low HDL level. Even among the users of OCs duration of use did affect serum HDL level, though duration of use for more than 5 years had significantly raised levels of total cholesterol, LDL and triglycerides.

In study conducted by Walsh and Sacks ${ }^{13}$ on 11 healthy women 5 of them were taking OCP, plasma triglyceride level was found increased among the users of OCP which goes in favour of our study. In another study ${ }^{14} 35$ women were given combined OCP containing the same amount of ethinyl estradial and either levonergestrel or desogestrel. After 2 months treatment there were significant rise in HDL and triglyceride.

The results of this study contrasts with the findings of the present study. HDL level is found not to be increased in this study as the people of Bangladesh intakes more carbohydrate as their food habit. The study conducted by Wamala et al ${ }^{15}$ to examine the relationship between socioeconomic status and full lipid profile in healthy middle-aged women in 
Sweden. It comprises 300 healthy Swedish women between 30 and 65 years. Of the lipid variables, low HDL levels were most consistently associated with low socioeconomic status. This study goes in favour of this present study.

\section{Conclusions}

In conclusion serum total cholesterol is significantly higher among the women who use low dose OCP containing $30 \mu \mathrm{gm}$ EE plus $150 \mu \mathrm{gm}$ LNG than without OCP users. Again serum triglyceride and LDL-cholesterol are also significantly raised in the OCP users. However HDL shows no difference in OCP users. Further large scale multicentre study should be performed to avoid the selection bias of the study.

\section{References}

1. Minozzi M, Costantino D, Guaraldi C, Unfer V. The effect of a combination therapy with myo-inositol and a combined oral contraceptive pill versus a combined oral contraceptive pill alone on metabolic, endocrine, and clinical parameters in polycystic ovary syndrome. Gynecological Endocrinology. 2011;27(11):920-4

2. Junge W, Mellinger U, Parke S, Serrani M. Metabolic and haemostatic effects of estradiol valerate/dienogest, a novel oral contraceptive. Clinical drug investigation. 2011;31(8):573-84

3. Kriplani A, Periyasamy AJ, Agarwal N, Kulshrestha V, Kumar A, Ammini AC. Effect of oral contraceptive containing ethinyl estradiol combined with drospirenone vs. desogestrel on clinical and biochemical parameters in patients with polycystic ovary syndrome. Contraception. 2010;82(2):139-46

4. Berenson AB, Rahman M, Wilinson G 2009. Effect of injectable and oral contraceptives on serum lipid, Obstetrics \& $\quad$ Gynecology. 2009; http://journal.lww.com/greenjournal/abstract/2009 p. 1 of 1

5. Naz F, Jyoti S, Akhtar N, Afzal M, Siddique YH. Lipid profile of women using oral contraceptive pills. Pakistan J Biological Sciences 2012;15(19):947
6. Lidegaard $\varnothing$, Løkkegaard E, Jensen A, Skovlund CW, Keiding N. Thrombotic stroke and myocardial infarction with hormonal contraception. New England Journal of Medicine. 2012;366(24):2257-66

7. Carlson LA, Bottiger LE, Ahfeldt PE. Risk factors for myocardial infarction in the Stockholm prospective study. Acta Med Scand 1997; 206: 351-60

8. Van Vlijmen EFW, Brouwer J-LP, Veeger NJGM, Eskes TKAB, De Graeff PA, Van Der Meer J 2007. Oral contraceptives and the absolute risk of venous thromboembolism in women with single or multiple thrombophilic defects. Arch Intern Med 2007;67:282-9

9. Kashefa K, 2006. 'Effect of low-dose oral contraceptives on serum lipids', (Thesis), Bangabandhu Sheikh Mujib Medical University

10. Nahar K 1986, 'Clinical and Biochemical study of prolonged oral pill users', (Dissertation), Bangladesh College of Physicians \& Surgeons, Dhaka

11. Teichmann A. Metabolic Profile of six oral contraceptives containing norgestimate, gestodene and desogestrel. Int J Fertil Menopausal Study 1995;40:98-104.

12. Coata G, Ventura F, Lombardini R, Ciuffetti G, Cosmi EV, Renzo GCD. Effct of low-dose oral triphasic contraceptives on blood viscosity, coagulation and lipid metabolism. Contraception 1995; 52:151-157

13. Walsh BW, Sacks FM.Effect of Low Dose Oral Contraceptives on Very Low Density and Low Density Lipoprotein Metabolism. The American Society for Clinical Investigation 1992;91:2126-2132

14. Zimmerman Y, Eijkemans MJ, Bennink HC, Blankenstein MA, Fauser BC. The effect of combined oral contraception on testosterone levels in healthy women: a systematic review and meta-analysis. Human reproduction update. 2014;20(1):76-105

15. Wamala SP, Wolk A, Schenck-Gustfsson K, Orth-Gomer K. Lipid Profile and Socioeconomic Status in Healthy Middle Aged Women in Sweden. J Epid Community Health 1997;58:400-407

16. Ågren UM, Anttila M, Mäenpää-Liukko K, Rantala ML, Rautiainen H, Sommer WF, Mommers E. Effects of a monophasic combined oral contraceptive containing nomegestrol acetate and $17 \beta$-oestradiol compared with one containing levonorgestrel and ethinylestradiol on haemostasis, lipids and carbohydrate metabolism. The European Journal of Contraception \& Reproductive Health Care. 201;16(6):444-57

17. Masimasi N, Sivanandy MS, Thacker HL. Update on hormonal contraception. Cleveland Clinic J Med 2007;74(3):186-98 